\title{
LACTATIONAL AMENORRHOEA AND CONTRACEPTIVE PRACTICE
}

\author{
DULITHA N. FERNANDO AND PRIYANI E. SOYSA \\ Faculty of Medicine, University of Colombo, Sri Lanka
}

AND

K. ABEYWICKR AMA

Department of Mathematics, University of Colombo, Sri Lanka.

(Date of receipt : 25 August 1986)

(Date of acceptance : 20 April 1987)

\begin{abstract}
Lactational amenorrhoea represents an important child spacing mechanism in many developing countries. The contribution made by lactation as a method of contraception needs to be assessed for a given situation depending on the infant feeding practices and the pattern of postpartum amenorrhoea. A community based study on a sample of mothers from 'urban', 'town' and 'rural' sectors provides the above information and also highlights the differences between these sectors. Such information need to be taken into consideration in formulating policies related to family planning programmes in order to identify appropriate timing for the introduction of such programmes.
\end{abstract}

\section{Introduction}

The contraceptive effects of lactation has been recognised in various cultures for centuries. Following childbirth, each woman experiences a period of temporary infecundability, during which there is no ovulation, hence a period of amenorrhoea follows on childbirth. Since amenorrhoea is more easily observed than ovulation, the period of amenorrhoea is taken as indicative of post-partum non-susceptible period.

Breastfeeding practices appear to be a principal determinant of lactational amenorrhoea. Many studies have shown that in the absence of breastfeeding, post-partum amenorrhoea commonly lasts about two months and where breastfeeding is prolonged, this would last between one to two years. $^{3,9}$ An analysis of breastfeeding patterns in 25 sub-populations in nine countries showed that variations in the proportion of women breastfeeding explained about $85 \%$ of the variance between populations in the proportion of menstruating women. ${ }^{1}$. The contribution that prolonged breastfeeding could make towards increasing the birth interval thus influencing the fertility pattern has also been studied. ${ }^{8}$

Even though a positive relationship between the duration of breastfeeding and postpartum amenorrhoea has been identified, considerable 
differences in the patterns have been observed between countries as well as within countries. ${ }^{10}$ Differences in the frequency of suckling ${ }^{4}$ and the nutritional status of the women have been identified as likely contributory factors. ${ }^{7}$

For an individual woman, the reliability of using breastfeeding per se as a method of family planning, remains doubtful. As the average duration of breastfeeding in many communities decline, family planning programmes need to pay emphasis on providing contraception before an unwanted pregnancy occurs.

\section{Materials and Methods.}

A cross-sectional study to identify infant feeding practices was carried out in twelve of the twenty four districts of Sri Lanka. Approximately $70 \%$ of the population of Sri Lanka reside in the districts included in the study. ${ }^{11}$

Thirty study areas from each of the three sectors ie. urban, town and rural, were identified using the technique of "probability proportional to size" sampling, using the data available from the Census. From each of these areas, one study cluster was identified randomly. From each of these clusters, thirty children whose ages were one year and below, on the day of the interview were identified, thus including approximately 900 motherchild pairs from each of the three sectors.

The information was collected using an interviewer administered precoded questionnaire, which was pre-tested and modified prior to use in the survey. Part I of the questionnaire contained information related to the household while Parts II and III contained information related to the infant feeding practices and those on the mother (which included data on menstruation and contraceptive practices).

A group of family health workers were trained to collect the information. Field supervisors were responsible for cross-checking the data at the field level and in supervising the work of the field investigators. All questionnaires were checked manually as well as edited using computer facilities.

\section{Results}

Majority of women initiated breastfeeding as shown in Table 1. The data on infant feeding was obtained by questioning the mother as to the feeding of the child on the day preceeding the interview, thus minimising recall error. Even though the majority of women initiated breastfeeding, most mothers 
Table 1. Initiation of Breast Feeding

\begin{tabular}{lccc}
\hline & & Number of Mothers & \\
\cline { 2 - 4 } & Urban & Town & Rural \\
\hline Initiated breastfeeding & $892(98.0 \%)$ & $896(98.0 \%)$ & $901(99.0 \%)$ \\
$\begin{array}{l}\text { Not initiated - } \\
\text { due to "no milk" }\end{array}$ & $7(0.9 \%)$ & $4(0.4 \%)$ & $3(0.3 \%)$ \\
$\begin{array}{l}\text { mother's illness } \\
\text { child's illness }\end{array}$ & $3(0.3 \%)$ & $5(0.5 \%)$ & - \\
other reasons & $1(0.1 \%)$ & $2(0.2 \%)$ & - \\
No information & $4(0.4 \%)$ & $2(0.2 \%)$ & $1(0.1 \%)$ \\
\hline Total & $3(0.3 \%)$ & $3(0.3 \%)$ & $2(0.2 \%)$ \\
\hline
\end{tabular}

included "other milks" specially powdered milk, in the feeding of their children, early in infancy. Table 2 shows that by the age of three (3) months, $55 \%$ of urban, $53 \%$ of town and $40 \%$ of rural mothers had introduced powdered milks. Data related to menstruation obtained from the mothers do include a certain amount of recall even though the maximum period of recall was one year. In $92 \%$ of the interviews, the mothers responded to this question thus improving the quality of this information.

The proportion of women in whom menstruation had returned, was studied in relation to the breastfeeding pattern (Table 3 ). In each sector, the proportion of women in whom menstruation had returned was significantly higher among those who had discontinued breastfeeding.

The age of the child is an important factor that influences the pattern of feeding as well as the return of menstruation, hence was taken into consideration in further analysis (Table 4). It is observed that for all age groups, the proportion of women in whom menstruation has returned was comparatively higher among the group that had stopped breastfeeding. The exception to this observation is that made for the younger age groups in the 'Town' and 'Rural' sectors, the likely reason being the very small number of women who had stopped breastfeeding, in these age groups. It is seen that as the age of the child increases, the magnitude of the difference between the two groups decline. This is specially marked from $7-8$ months onwards.

The family planning acceptance pattern was studied in relation to the 'return' of menstruation (Table 5). A total of 22 mothers out of 2665 in 


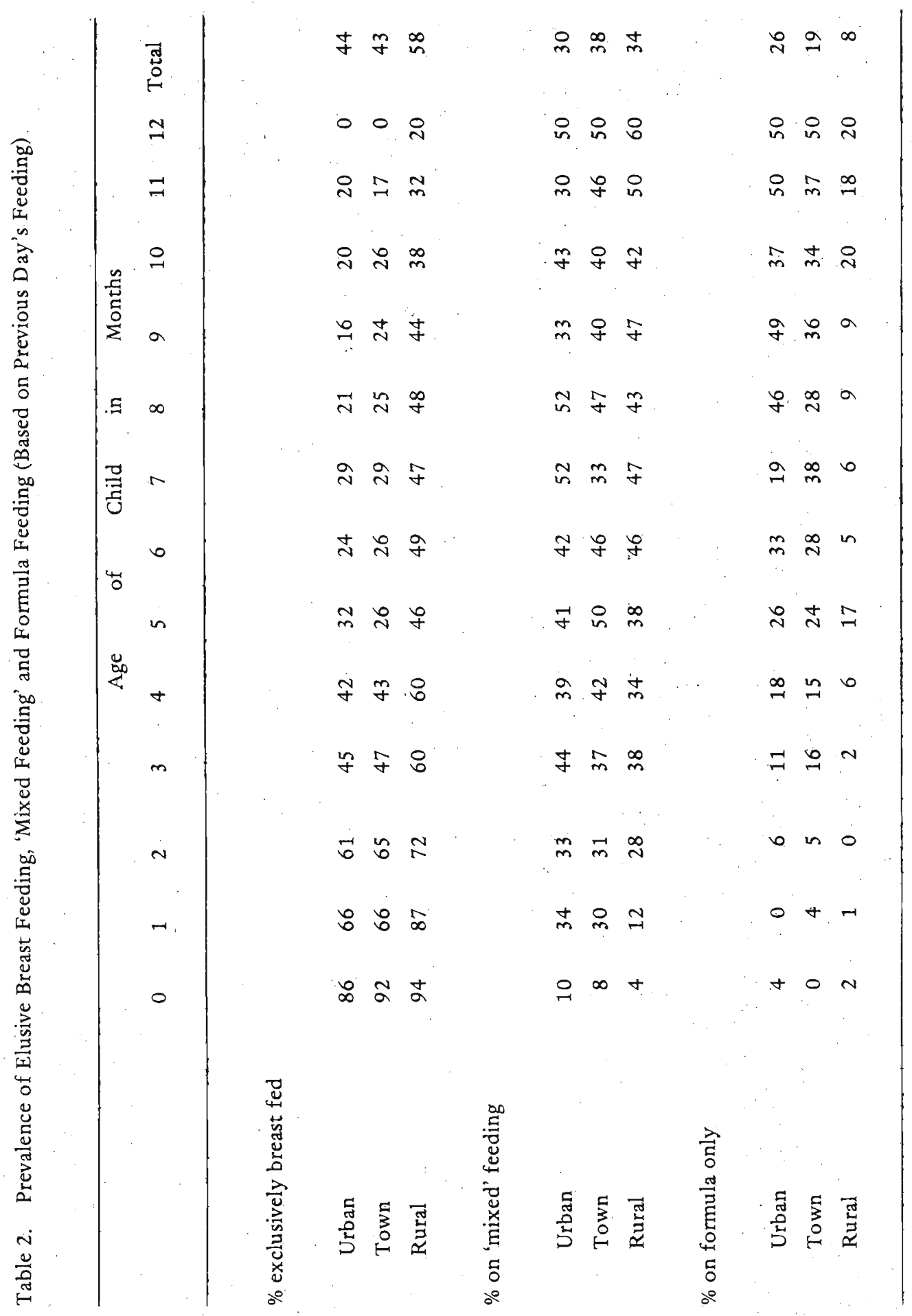


Table 3. Pattern of amenorrhoea in relation to breastfeeding practices.

A. URBAN

$\begin{array}{ll} & \\ \text { Breastfeeding } & \text { Yes } \\ & \text { No } \\ & \text { Total }\end{array}$

B. TOWN

\begin{tabular}{|c|c|c|c|c|}
\hline & & & & \\
\hline & & Yes & No. & Total \\
\hline Breastfeeding & Yes & 394 & 331 & 725 \\
\hline & No & 148 & 23 & 171 \\
\hline & Total & 542 & 354 & 896 \\
\hline & & $\begin{array}{l}\text { No } \\
x^{2}\end{array}$ & $\begin{array}{l}-16 \\
1, p\end{array}$ & \\
\hline
\end{tabular}

C. RURAL

\begin{tabular}{|c|c|c|c|c|}
\hline & & \multicolumn{3}{|c|}{ Menstruation Returned } \\
\hline & & Yes & No. & Total \\
\hline \multirow[t]{4}{*}{ Breastfeeding } & Yes & 341 & 481 & 822 \\
\hline & No & 52 & 15 & 67 \\
\hline & Total & 393 & 496 & 889. \\
\hline & & \multicolumn{3}{|c|}{ No information -18} \\
\hline
\end{tabular}

Menstruation Returned

\begin{tabular}{crc} 
Yes & No. & Total \\
\hline 399 & 278 & 677 \\
183 & 17 & 200 \\
\hline 582 & 295 & 877 \\
\hline
\end{tabular}

No information - 33

$\mathrm{x}^{2}-37.1, \mathrm{df}-1, \mathrm{p}<0.001$

$\mathrm{x}^{2}-59.8, \mathrm{df}-1, \mathrm{p}<0.001$

Menstruation Returned 


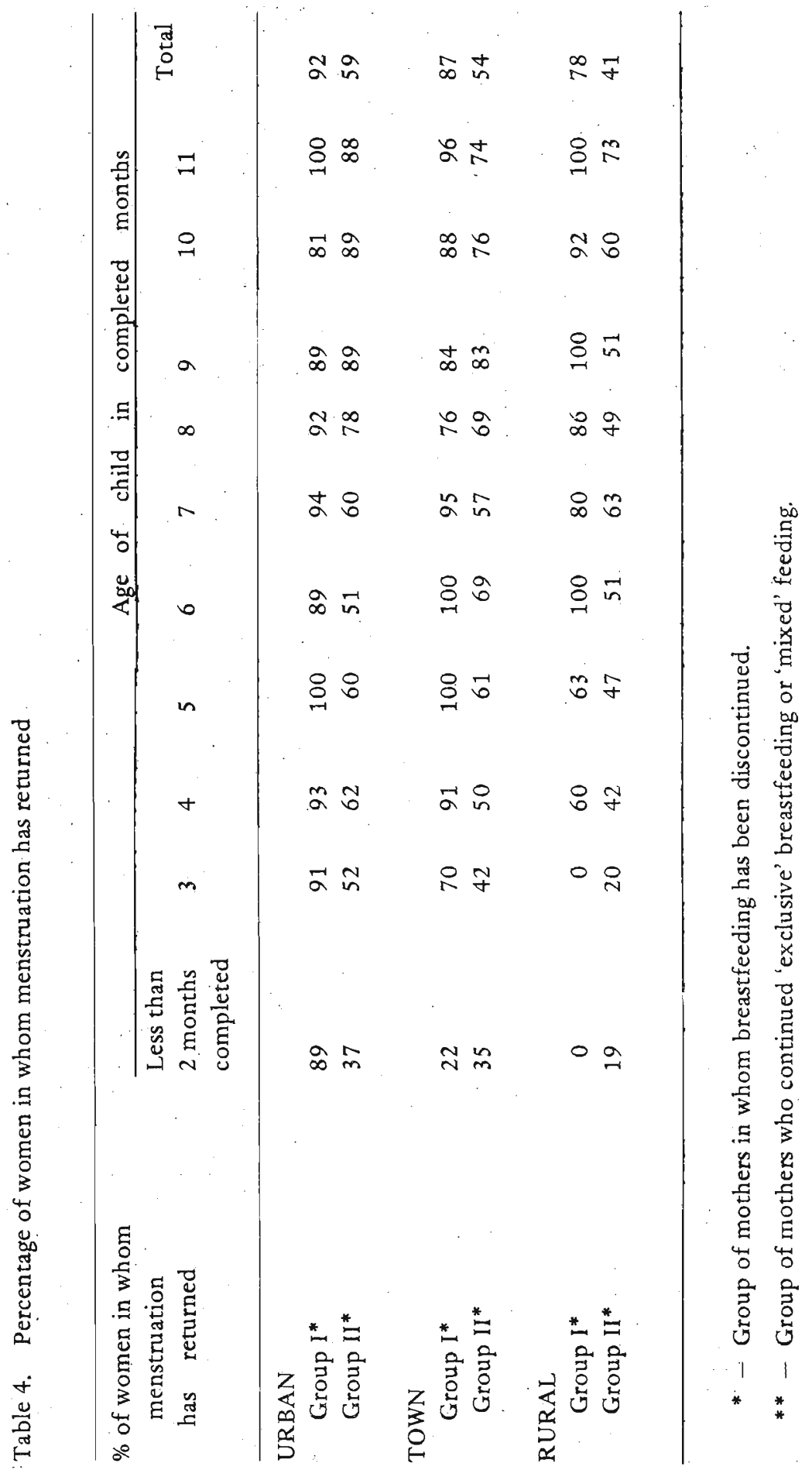




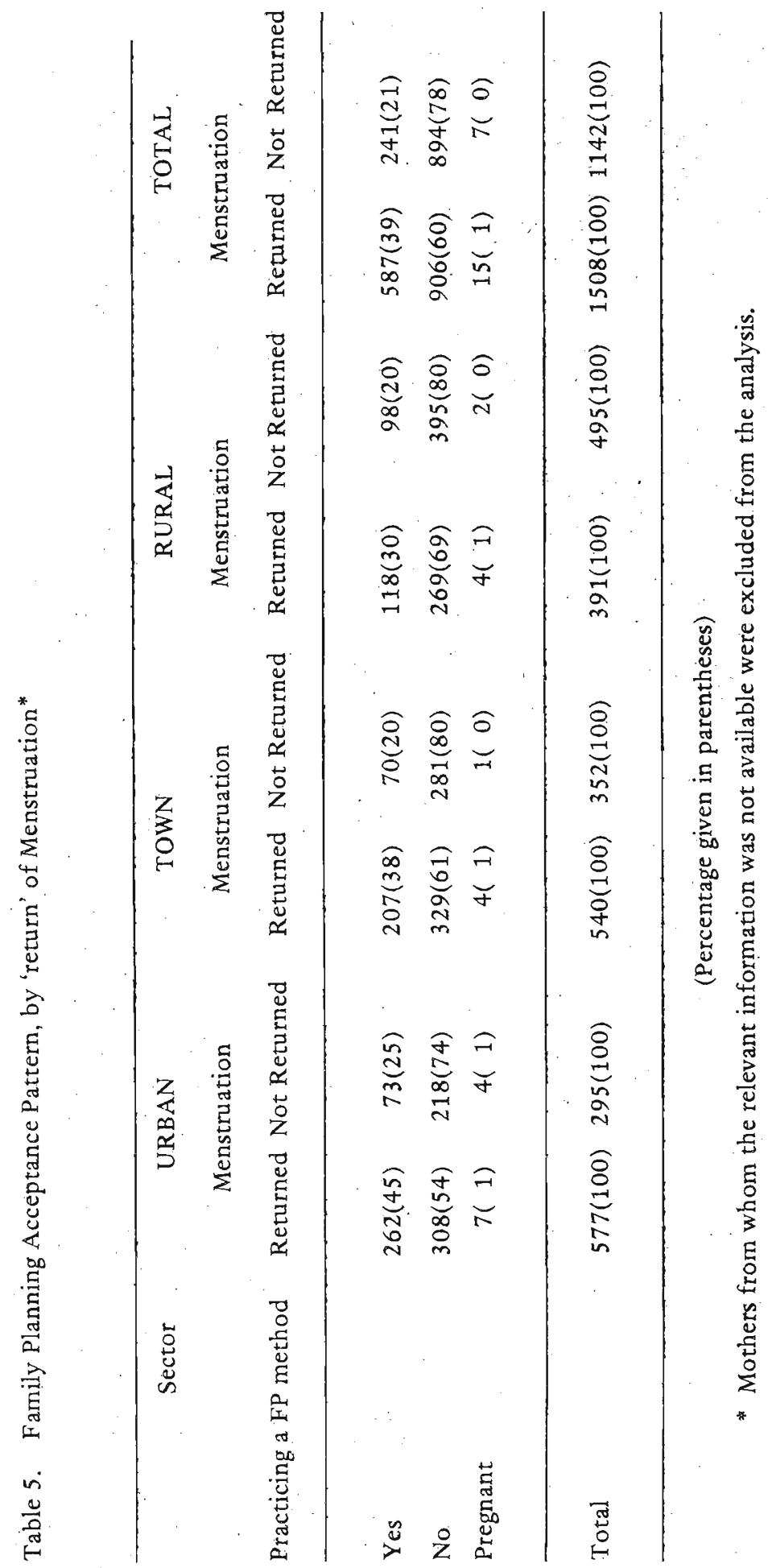


whom the information was available i.e. $0.8 \%$ were pregnant at the time of the interview. One third of this group had got pregnant before menstruation resumed.

In the total sample, $21 \%$ of the group of women in whom menstruation had not returned, had adopted a method of family planning compared to $39 \%$ among the group in whom menstruation had returned. Comparatively higher proportions of women in the urban sector had accepted a method of contraception.

In this study, the practice of the following methods of contraception were inquired into i.e. surgical methods (male and female) loop, pills, IUCD, Injectables, Condom, safe period and other natural methods. Such information was available from $76 \%$ of the group of women who were practicing a method of family planning. Table 6 shows that the commonest methods adopted were the surgical methods and the 'natural' methods. Of the women in whom menstruation had not returned, $58 \%$ had adopted a surgical method compared to $24 \%$ among the group in whom menstruation had returned. Inappropriateness of the use of hormonal methods and natural methods was indicated by the comparatively lower proportion of women in whom menstruation had not returned, who practiced these methods.

Table 6. Practice of contraceptive methods in relation to the status of menstruation.

\begin{tabular}{lccc}
\hline $\begin{array}{l}\text { Method of } \\
\text { Contraception }\end{array}$ & Returned & Nenstruation & Total \\
\hline $\begin{array}{l}\text { Oral contraceptives } \\
\text { IUCD }\end{array}$ & $79(18)$ & $13(6)$ & $92(14)$ \\
$\begin{array}{l}\text { Sterilization } \\
\quad \text { (male and female) }\end{array}$ & $41(9)$ & $12(6)$ & $53(8)$ \\
$\begin{array}{l}\text { Injections } \\
\text { Condom }\end{array}$ & $47(11)$ & $114(58)$ & $222(35)$ \\
Safe period and other & $59(13)$ & $8(4)$ & $55(9)$ \\
$\quad$ 'natural' methods. & $108(24)$ & $26(13)$ & $85(13)$ \\
\hline \multicolumn{1}{c}{ Total } & $442(100)$ & $24(12)$ & $132(21)$ \\
\hline
\end{tabular}

(Percentage given in parentheses)

\section{Discussion}

This study provides some information on the pattern of lactational amenorrhoea among a group of Sri Lankan women. However, the study 
cannot be considered a national level study, but is based on the information available from a representative sample of women with children under one year of age, living in twelve of the 24 districts of Sri Lanka, where $70 \%$ of the population reside.

The WHO collaborative study ${ }^{13}$ carried out in eight countries showed that among the non-breastfeeding (NBF) women, $80-100 \%$ were menstruating by $3-4$ months postpartum. In this study, comparable proportions were observed among mothers from the 'Urban' and 'Town' sectors. Valid conclusions cannot be drawn as the number of women belonging to the 'NBF' group in the 'Rural' sector is very small.

Among the 'breastfeeding' (BF) group, wider variations were observed in the proportion of women in whom menstruation has returned by $3-4$ months. They ranged from $1 \%$ in rural India to $57 \%$ among the 'urban' group in Ethiopia. ${ }^{13}$ The observations made in this study compare well with those made in the 'Urbanised' areas of the countries included in the WHO collaborative study.

The frequency and intensity of suckling is thought to influence the duration of infecundity. ${ }^{12}$ From the point of view of ensuring adequate child growth, it is necessary to stress the need to introduce complementary foods using locally available foods, as the child grows older. Introduction of such feeding practices is likely to reduce the frequency of suckling, thus influencing prolactin levels, milk production and eventually ovulation. The differences in the proportion of women who had menstruated, between BF \& NBF groups became smaller as the age of the child increases. This observation is likely to be due to the reduction of frequency of suckling among the older infants.

Even though a very high proportion of mothers did commence breastfeeding, most mothers did introduce formula milks and other complementary foods in early infancy. This information has important policy implications regarding family planning programmes, as it is necessary that such a program should be developed so as to provide contraception before an unwanted pregnancy occurs. Such decisions involve the identification of a specific time when infant suckling patterns change considerably, which may be an appropriate time to start contraception.

Absence of menstruation does not mean the absence of ovulation and it has been observed in the WHO study that up to $10 \%$ of the mothers who had got pregnant at the time of the interview had conceived before menstruation resumed. Only $0: 8 \%$ of women in the present study had got pregnant at the time of the interview, among whom a third had conceived before menstruation returned, thus indicating the need for the early introduction of family planning programmes. 
Different views have been expressed as to the timing of a programme to promote contraceptive practices. Jeliffe ${ }^{6}$ suggested that technical family planning methods need to be introduced on a community basis not later than about two months prior to the usual time of return of menses which need to be known for a particular situation. The concensus at the meeting of the World Health Organization and US National Research Council ${ }^{14}$ was that contraception should be initiated at a time when a quarter to one half of the lactating women resume menses. In view of the relevance of food supplementation, Howie ${ }^{5}$ observes that if the time at which food supplementation is to be introduced could be clearly defined, then it may be possible to link such a change with the start of contraception or change from a less effective method to a more effective method.

Taking the above views into consideration, from the data available in the present study it could be suggested that emphasis on family planning programmes should be made from about 4 months post-partum.

Another main area of concern are the methods of contraception that needs to be encouraged during lactation. Non-hormonal methods are generally preferred during this period, 9,12

It is necessary for all health workers to be aware of the link between infant feeding practices and matemal fecundity. This is of special importance as studies have shown that some categories of health workers are often misinformed about breastfeeding practices. ${ }^{2}$ They should be able to use relevant information to identify mothers who need protection and should be able to recommend appropriate methods of contraception.

\section{Acknowledgement}

The financial support provided by the World Health Organization for this study is gratefully acknowledged.

The authors wish to thank the Director General of Health Services, Professor of Paediatrics, University of Peradeniya, Professor of Paediatrics, University of Ruhuna, Director, National Institute of Health Sciences, Chief Medical Officer of Health, Colombo Municipality and many members of their staff for their assistance during the study.

\section{References}

1. BILLEWICZ, W.Z. (1979) J. Biosoc. Sci. $11: 141-151$.

2. BURGESS, A.P. (1980) J. Trop. Pediatr. 26 (5) : 168-171. 
3. CHEN, L.C., AHMED, S., GESCHER, M. \& MOSLEY, W.H. (1974) Population Studies 28 (2) : 277-297.

4. DELVOYE, P. \& ROBYN, C. (1980) J. Trop. Pédiatr. 26 (5) : 184-189.

5. HOWIE, P.W., MC NEILLY, A.S., HOUNTON, M.J., COOK, A. \& BOYLE, H. (1981) Br. Med. J. 283 (6294) 757-75.9.

6. JELlifFE, D.B. \& JELLIFFE, E.F. (1985) J. Trop. Pediatr. 31 (5) : 240-241.

7. LUNN, P.G., WATKINSON, M., PRENTICE, A.M., MORRELL, P., AUSTIN; S. \& WHITEHEAD, R.G. (1981) Lancet 1 : 1428-1429.

8. PAGE, H.J., LESTHAEGHE, R.J. \& SHAH, I.H. (1982) Illustrative Analysis Breastfeeding in Pakistan; Scientific Reports WFS No. 37: International Statistical Institute, Voorburg, Netherlands.

9. PEREZ, A., VELA, P., POTTER, R. \& MAUSICK, G.S. (1971) Population Studies $25(3): 491-503$.

10. Population Reports No. 24J (1981) Breastfeeding, fertility and Family Planning. Population information programme. The Johns Hopkins University, Baltimore, Maryland, USA.

11. Sri Lanka, Ministry of Plan Implementation; Department of Census and Statistics: Statistical Pocketbook of the Democratic Socialist Republic of Sri L.anka, 1981.

12. TYSON, J.E. (1977) Med. Clin. North Am. 61 (1): 153-163.

13. World Health Organization : Contemporary patterns of breastfeeding; Report on the WHO Collaborative Study. WHO Geneva 1981. 211 p.

14. World Health Organization/US National Research Council Meeting : Breastfeeding and fertility regulation - current knowledge and programme policy; (1983) Bull WHO $61: 371-382$. 